\title{
The Practicing of Teaching Mode under the Concept of Engineering Education
}

\author{
Liang CHANG \\ College of Computer Science and Technology, \\ Xi'an University of Science and Technology, \\ Xi'an, Shaanxi, China
}

Na LI

College of Computer Science and Technology, Xi'an University of Science and Technology, Xi'an, Shaanxi, China

\author{
Shangfu GONG * \\ College of Computer Science and Technology, \\ Xi'an University of Science and Technology, \\ Xi'an, Shaanxi, China
}

Fengzhi XU

College of Computer Science and Technology, Xi'an University of Science and Technology, Xi'an, Shaanxi, China

\begin{abstract}
Guided by the idea and essence of higher engineering education, this paper points out the problems and deficiencies of curriculum design, theory teaching and practical teaching in current talent training program. It develops the reform and practice of teaching contents, te aching methods and teaching links based on the cultivation of engineering qualities and practical innovation abilities from multiple aspects and channels. This paper researches the teaching model of "teaching reform based on engineering application and link integration courses", and explores the teaching methods of "double driving of problem and case, mutual promoting of in-class and extracurricular, and combination of theory and practice". The practice proves that it has good teaching effects.
\end{abstract}

Keywords-Engineering education; Talent training; Teaching reform; Teaching practice

\section{BACKGROUND AND SIGNIFICANCE}

The aim and essence of higher engineering education is to train advanced engineering and technical talents ${ }^{[1]}$. In the past decades, the higher engineering education in China has cultivated a large number of talents for construction and development of industry and society, supported the formation and development of our industrial system, and played an irreplaceable role in national construction and industrial development. However, due to the influence of traditional educational thought and blindly copying foreign higher education models, there are some problems in higher engineering education in China, such as the excessive scientific training scheme, the lack of engineering and the weak links in practice ${ }^{[2]}$. The evaluation system of talents training in most colleges and universities is oriented to emphasize papers, but contempt design, lack of practice and no project. They pay insufficient attention and investment to engineering education and entrepreneurial training of students and have scant cooperation between Industry, University and Research. The enterprises do not attach importance to the participation in the process of talent training. Many engineering colleges with good industry characteristics have a serious phenomenon of removing industry, so that their advantages and characteristics have desalination with obvious property of homogeneity. A series of problems lead to a sharp contradiction between talent training mode and talent demand. On the one hand, students' knowledge structure is difficult to meet the actual needs of enterprise; on the other hand, there is a fault in the enterprise's technical talents and it has become a bottleneck that will restrict development of enterprise. In the circumstances, higher engineering education returning to the nature of engineering has become a general trend.

In 2010, the ministry of education launched "excellent engineer education and training plan", according to the problems existing in Chinese current higher education and combining national industrial development with adjustment of talent demands relationship. In 2017, Fudan University, Tianjin University and other universities put forward an action of "new engineering subject", which will greatly promote our country from a big engineering education country to a powerful engineering education country. The purpose of this plan is to face the industry, the world and the future to cultivate a large number of high-quality engineering and technical personnel with strong innovation ability and meeting needs of economic and social development, and to provide talent support for construction of an innovative country.

\section{Higher ENGINEERING EDUCATION AND TEACHING CONCEPT}

In order to adapt to the requirements of modern large-scale projects, developed countries in the world have always attached great importance to research and reform of engineering education in their own countries, and have formed their own relatively perfect training system and scientific training mode ${ }^{[8]}$. At present, the international engineer training is divided into two major models. One model is the "Washington Agreement" membership model represented by the United States. That is, college students focus on basic engineering education while they are in school. After graduation, the society provides education in the professional field of engineers and students need pass a special examination and a professional qualification certification to become qualified engineers ${ }^{[3]}$. The second model is the 
European continental national model represented by Germany and France. That is, college students must complete the basic training of engineers while they are in school, and obtain a diploma degree of engineer at the time of graduation, which is also a professional qualification. Although these two training modes are different in form, they both pay attention to practical teaching and start engineering comprehensive training earlier. Through practical courses or project development, practical engineering problems are brought into classes, and students are trained for practical operation skills in enterprises.

Higher engineering education attaches great importance to practical skills teaching ratio ${ }^{[4][5]}$. In many foreign engineering universities, practical teaching accounts for a large proportion ${ }^{[2]}$, such as Stanford University in the United States having 83 practical credits of engineering major accounting for 43 percents of the total credits. Its multi-level project training and various forms of extracurricular practice constitute a complete practical teaching system. The open practical teaching environment and numerous practice training opportunities in social and enterprise provide a good training platform for developing abilities. At the same time, the characteristic humanistic quality education system pays attention to the education of students' laws and regulations, the ability of expression, the ability of communicating with people, the cultivation of cooperation spirit, and organically combines quality education with study of professional knowledge. The engineering education in American universities is characterized by its emphasis on professional basic theory education, the idea of lifelong learning, the harmony of engineering science with society and environment, and the sense of responsibility and professional ethics in engineering practice. In German engineering education, practical teaching plays an important role and occupies a large number of hours in the teaching plan. For example, in Stuttgart University, the ratio of practical courses to theory courses in the basic study stage of mechanical engineering department is 1 to 2 , and the proportion in the major study stage is even higher. There are a variety of production practices of 26 weeks, thus ensuring the characteristics of engineering education.

\section{REVISION OF TALENT TRAINING SCHEME FROM ENGINEERING EDUCATION}

Talent training scheme is the general principle of higher education and teaching, relating to the main content of talent training. The establishment of talent training system of a university is a process of continuous improvement, which not only needs its own characteristics and features, but also needs to meet the requirements of sustainable development. According to the connotation and development trend of engineering education, we should pay attention to national social demands and certification standard of engineering education in the revision of the new talent training plan ${ }^{[6]}$. The main ideas of the revision of talent training scheme should focus on the following aspects.

- Taking regional economy and industry development demands as the guidance, aiming at focusing on engineering application and training innovation ability, universities should advocate the harmonious development of knowledge, ability and quality, adhere to talent cultivation concept of 'taking morality first, taking ability as heavy and comprehensive development", stick to international view of "facing the society, facing the world and facing the future", and follow rules of higher engineering education for training engineering applied talents for national economic construction.

- In terms of personnel training types, according to the orientation of different universities, universities should stick to regional orientation, face to the whole country, serve leading industries, local economic and social development, and cultivate advanced engineering and technical talents with features of "solid foundation, plain style, hard work, honesty and be bold in making innovations."

- In the aspect of professional curriculum system and teaching content, the university should reflect industry characteristic of informatization and application advantages. That is, on the basis of relevant majors, universities need integrate computer science, information technology and other multidisciplinary knowledge. Then, universities should extend course content by combining industry engineering demands to form a curriculum system with distinctive industry characteristics.

- For setting course system, it should be guided by engineering paradigm. The university need emphasize comprehensiveness, practicality and innovation of engineering itself. One is to pay attention to integration of knowledge, ability and training quality. The other is to focus on integration of training technical elements and non-technical elements. To strengthen comprehensive training link, to enhance students' abilities of engineering application and solving complex engineering questions and to cultivate students' spirits of teamwork and innovation.

In the aspect of content organization and order in curriculum plan, the university should pay attention to theoretical knowledge which supports each other as warp, a series of abilities as weft. Like interweaving of warp and weft, this idea can realize combination of theory and practice, as well as achieve organic integration of knowledge, ability and quality training.

\section{PROFESSIONAL TEACHING REFORM AND PRACTICE IN ENGINEERING EDUCATION}

Engineering professional course is an important link for students to learn engineering knowledge, train mode of thinking in engineering and develop ability of solving complex engineering problems ${ }^{[7]}$. Engineering knowledge belongs to complex knowledge with characteristics of strong comprehensiveness, systematicness and practicality, many forms of expression, and involving a wide range of knowledge. Therefore, teaching of engineering courses is more difficult than vivid arts courses and abstract and complete science courses. 


\section{A. Main problems in professional courses teaching.}

At present, the main problems existing in engineering courses teaching in our university are as follows: (1) In the course setting, the curriculum system is constructed according to hierarchy of public courses, basic courses, basic professional courses, professional courses and elective professional courses. This method is helpful for students to master knowledge system of subjects, but it is not enough for engineering practice. (2)The current curriculum teaching mode is more inclined to scientific education model, and pays more attention to teaching abstract knowledge and concepts which separate from engineering background. This existing mode is lacking of systematicness and engineering practicability, cannot fully reflect characteristics of engineering knowledge, and cannot conform to rules of students' cognitive process for engineering. (3) The teaching method takes teaching by teachers in classroom as the principal thing. There is a phenomenon of tradition and singleness. It will cause that scientific thinking, training and stimulation of active learning of students are not enough. (4)The combination of practical teaching and theoretical teaching is not tight, the idea of practical teaching is old, the majority of students in training are in passive practice, and their enthusiasm is weak. As a result, their practical ability training has low efficiency. (5) Students are used to carrying out study of engineering knowledge by using learning methods of middle school for scientific theory knowledge. In the study, they pay more attention to do exercise and rote learning, so they cannot really master and apply knowledge.

\section{B. Teaching reform based on engineering application and link integration courses}

As the main way to learn engineering knowledge, professional courses must follow characteristics of engineering knowledge in teaching, including comprehensiveness, practicality, relevance and going forward one by one. The existing curriculum setting based on subject system, and engineering knowledge is scattered in each individual curriculum. It has a lack of effective contact with an engineering practical situation. Students are faced with an independent curriculum, and the study of knowledge stays at the point. Without extending to lines and surfaces, it is difficult to form a complete knowledge system. The result is that making knowledge learning become "only trees, not forests". In engineering course system, there exists intersection and fusion of subjects, and knowledge correlation and fusion among contents of courses. In order to promote extension from knowledge point to knowledge range and construct knowledge system, it is necessary to link scattered individual courses organically through engineering practice, so that students can learn knowledge, make synthesis of knowledge and make relevance to engineering practice under the guidance of a situational main line.

Taking the major of network engineering as an example, in teaching reform of professional course, the exploration and practice of an integrated course teaching mode which links network integration and engineering design comprehensive experiment system with multiple professional courses has been developed. For students of network engineering, the university has set up many important basis professional courses, such as basis of electronic technology, principle of computer composition, basis of data communication technology, principle of computer network, and network protocol. How to combine these main principles and conceptual courses with engineering knowledge and ability, so that students can truly learn and master abilities to plan, design and build computer information network in the practical application of society. The methods which have network integration and implement and management of engineering projects makes an effective improvement of engineering practice ability through the links between multiple related courses and practical training of engineering application.

Cultivating engineering ability of students can be through three-level links. The first level is experiment cognition. Before the course, students should have a preliminary perceptual understanding of engineering knowledge and application by visiting and understanding practical application system, and learning composition and basic working principles of system. The second level is systematic course learning. In teaching, application cases should be introduced into course teaching. Through theoretical study and association with engineering practice, primary perceptual recognition of students can be gradually raised to integration and understanding of knowledge. The third level is professional comprehensive experiment. After completion of a professional course, through integrating the knowledge what they have learned and combining with engineering applications, a two-week network comprehensive experiment should be arranged to promote students to gradually improve and transform engineering knowledge to engineering abilities.

\section{Teaching reform of professional courses based on research learning method}

In the talent training scheme based on subject system, engineering knowledge is included in various professional courses. Students can obtain the basis of constructing their own engineering knowledge system through studying professional courses. Traditional teaching of professional courses mainly adopts the method of 'both teaching and experiment in-class". The form of classroom teaching is basically that teachers speaking and students listening. This teaching method highlights the role of teachers, while students as main body of learning are in a passive state, and their initiative and enthusiasm of learning are difficult to bring into play. At the same time, it limits formation of students' selfthinking. Curriculum experiments are mainly designed by teachers and lack of connection with engineering background. It will weaken cultivation of students' ability to apply knowledge.

In view of problems existing in traditional teaching methods of professional courses, this paper puts forward and carries out a teaching method of "double driving of problem and case, mutual promoting of in-class and extracurricular, combination of theory and practice". This method divides course teaching into three stages, they are before class, during class and after class. 
Before the course, students can get basic knowledge and application of course through the second classroom of extracurricular in the form of science lectures and situational engineering application examples. It can lead to related problems for students. In the process of course teaching, the university can adopt research learning method to carry out problem-based learning, and use cases and problems to promote classroom teaching, arouse interests of students, and guide students to think. For example, in the study of network protocols, because of abstraction and conceptualization, it is difficult for students to understand and master knowledge. Through classroom teaching, the university can carry out project-based learning after class, make extracurricular survey and study on related knowledge application, and set up student practice groups based on management of tutorial system. Students can find out and understand application background of network protocols by investigation, and master its working principle by discussion and study. In this way, they can study and solve problems, and obtain abilities of engineering application from theoretical learning.

The research results of study for students are displayed and exchanged in the students' classroom and flipped classroom. After course teaching, a series of comprehensive experiments of network engineering are set up to make students achieve consolidation of knowledge and improve fostering abilities through relevant practice in the process of continuous fusion and comprehensive application of knowledge. At the same time, in the process of course teaching, it can guide students to participate in extracurricular innovation practice activities, scientific research projects of teachers and various kinds of innovation and entrepreneurship competitions, such as extracurricular innovation experiments, innovation competitions of network security, engineering training competitions, extracurricular science and technology activities competition of challenge cup and so on. Through the training of projects with intersection of multiple disciplines and comprehensive knowledge, it can further foster students' innovation ability and knowledge application ability.

\section{To adopt practice teaching mode of tutorial system}

To adopt practice teaching mode of tutorial system, means that give full play to self-motivated learning practice spirit of students, adopt a method of "centralized teaching, guidance in group and comprehensive evaluation" to carry out teaching, and complete guiding work of experiments according to a principle of 'teachers put forward framework and requirements; students set up platforms and do experiments". This can improve enthusiasm and independence of experiments for students, and effectively enhance their abilities to solve problems and team consciousness. The experimental teaching mode is that "students as main body, optional experiment, independent construction and teacher guidance". The comprehensive experiment of tutorial system mainly includes analysis of engineering problem, design of experimental scheme, and independent construction of system and so on. Through the links of integrated experimental system, experimental test and result analysis, experimental demonstration and reply work, the whole experiment process mainly makes the student complete independently, while the teacher mainly plays the leading role.

\section{CONCLUSIONS}

Directed at returning to essence of engineering education, aiming at problems faced in training and implementation of applied talents in universities at present, this paper makes a deep research and analysis by combining engineering education with application-oriented transformation. Based on general standards of engineering certification and combined with changes of social and economic development for talent training demands, this paper points out problems and shortcomings of current talent training programs in the aspects of curriculum design, theoretical teaching and practical teaching. It carries out reform and practice of teaching contents, teaching methods and teaching links in cultivation of engineering quality and practical innovation ability through various aspects and channels. This paper puts forward the teaching model of "course teaching reform based on engineering application and link integration". It explores and practices the teaching method of "double driving of problem and case, mutual promoting of in-class and extracurricular, and combination of theory and practice". The exploration and implement of program proved that this method has good teaching effects.

\section{REFERENCES}

[1] Shen Chunying, Zhang Hua. Study on the effectiveness evaluation of engineering education training objective [J]. Journal of higher education, 2016 (4): 175-176. (In Chinese)

[2] Pu Yu. Study on the ability development of American engineering bachelor [J]. Journal of Dalian university of technology, 2010(4):70-74. (In Chinese)

[3] Fang Zheng. Comparison of engineering education certification system for signatories of Washington agreement $[\mathrm{J}]$. Higher education development and evaluation, 2014 (4):66-76. (In Chinese)

[4] Wang Wanqiang, Zhang Junfang. Research and practice of engineering training teaching model based on engineering education specialty authentication [J]. Education and Teaching Forum, 2016 (23):150-151. (In Chinese)

[5] Han Feng xia, Zheng Jun. Reform of engineering train ing teaching based on engineering education specialty authentication [J]. Experimental technology and management, 2015 (10):178-181. (In Chinese)

[6] Gong Shangfu, Chen Junjie. Promoting teaching quality engineering based on curriculum construction [J]. University education research, 2009(5):206-207. (In Chinese)

[7] Liu Bao, Li Zhengang. Reform of college classroom teaching model based on engineering education specialty authentication [J]. Heilongjiang higher education study, 2017 (4):157-160. (In Chinese)

[8] Xie Heping. Comprehensive capacity-building efforts to train innovative talents with international competitiveness [OL].
[ http://www.edu.cn/edu/cooperate/dxjx/201607/t20160708_1428152.sht $\mathrm{ml}$. (In Chinese) 